\title{
Structural behaviour and design criteria of under-deck cable-stayed bridges subjected to seismic action
}

\author{
Alfredo Camara ${ }^{1} *$, Ana M. Ruiz-Teran ${ }^{2}$ and Peter J. Stafford ${ }^{2}$ \\ ${ }^{1}$ Department of Mechanics and Structures, School of Civil Engineering, Technical University of Madrid, Spain \\ ${ }^{2}$ Department of Civil and Environmental Engineering, Imperial College London, UK
}

\begin{abstract}
SUMMARY
Under-deck cable-stayed bridges are very effective structural systems for which the strong contribution of the stay cables under live loading allows for the design of very slender decks for persistent and transient loading scenarios. Their behaviour when subjected to seismic excitation is investigated herein and a set of design criteria are presented that relate to the type and arrangement of bearings, the number and configuration of struts, and the transverse distribution of stay cables. The nonlinear behaviour of these bridges when subject to both near-field and far-field accelerograms has been thoroughly investigated through the use of incremental dynamic analyses. An intensity measure that reflects the pertinent contributions to response when several vibration modes are activated was proposed and is shown to be effective for the analysis of this structural type. The under-deck cable-stay system contributes in a very positive manner to reducing the response when the bridges are subject to very strong seismic excitation. For such scenarios, the reduction in the stiffness of the deck because of crack formation, when prestressed concrete decks are used, mobilises the cable system and enhances the overall performance of the system. Sets of natural accelerograms that are compliant with the prescriptions of Eurocode 8 were also applied to propose a set of design criteria for this bridge type in areas prone to earthquakes. Particular attention is given to outlining the optimal strategies for the deployment of bearings.
\end{abstract}

KEY WORDS: under-deck cable-stayed bridges; nonlinear dynamics; Eurocode 8; bridge bearings; seismic response; incremental dynamic analysis; near-field effects; intensity measure

\section{INTRODUCTION}

Conventional and extradosed cable-stayed bridges are both routinely recognized as classical solutions using girders with external prestressed cables (stays) above the deck. Consequently, there are many detailed references covering their behaviour and design (e.g. [1-3]), including papers specifically about their seismic behaviour (e.g., [4, 5]).

Under-deck cable-stayed bridges (UD-CSB) represent an efficient and innovative way to span medium lengths, of around $80 \mathrm{~m}$, with a single isostatic span. Bridges with the cable system located below the deck have the following main advantages over single-span structures without cablesystems [6]: enhanced structural efficiency, resulting from the greater contribution of axial response over flexural response; greater construction possibilities; efficient use of materials resulting from the greater slenderness, with direct economic and sustainability implications; and, arguably, greater aesthetic attributes arising from the geometric configuration of the cables. Only a limited number of these bridges have been constructed worldwide, probably because of the requirements for vertical

*Correspondence to: Alfredo Camara, Department of Mechanics and Structures, School of Civil Engineering, Technical University of Madrid, Spain.

E-mail: acamara@ciccp.es 
clearance below the deck and the lack of knowledge about their dynamic response. However, it is worth noting that many of those that have been constructed are located in highly-seismic areas like Japan.

The work of Ruiz-Teran and Aparicio [6-14] currently represents the main source of research on the topic of UD-CSB. These works establish the state of the knowledge, identify bridges that have been constructed with this typology, address their structural behaviour, and propose design criteria. Unfortunately, no specific research dealing with the seismic response of UD-CSB has been found in the academic literature. To contribute towards filling this gap, the nonlinear seismic response of this bridge typology is assessed in the present work through IDA [15] and code compliant validations.

To evaluate the expected response of the structure under several earthquake-induced groundmotions, subjected to different scaling factors in the IDA, efficient intensity measures (IM) should be employed to reduce the conditional dispersion of the response estimates. There is a significant body of knowledge associated with the selection of intensity measures for typical building structures. The most traditional and commonly used proposals are based on properties of the accelerogram like the PGA, or Arias intensity, but often also combine structural properties, like the spectral acceleration associated with the fundamental period of the structure $S_{\mathrm{a}}\left(T_{1}\right)$ [16]. This latter IM has demonstrated great effectiveness in structures governed by their first vibration mode. However, if higher modes make important contributions to the response of the structure, or there are significant period elongations because of material damage, the efficiency of $S_{\mathrm{a}}\left(T_{1}\right)$ is reduced. Some recent proposals for IMs aim to consider the nonlinearity of the structures response. Specifically, Luco and Cornell [17] proposed an IM based on the multimodal response and inelastic displacements, employing a special participation factor that takes into account the interstory displacements and different modal properties. Nowadays, the selection of appropriate IMs is a topic of ongoing research and a thorough discussion of the problem is beyond the scope of the present work. Nevertheless, a specific IM has been proposed for use in this study, providing information about the effect of different design decisions on the seismic response of the structure. In this direction, there are already proposals in the literature (e.g., $[18,19])$.

The seismic analyses in this work make use of the canonical bridges proposed by Ruiz-Teran and Aparicio [8]. These bridges have been designed for scenarios where the load combinations related to persistent situations govern the design. That is, accidental loads, including the effects of earthquakes, were not critical for the scenarios previously considered and the sections and reinforcement details of the design reflect this. Therefore, the deck does not contain confining reinforcement.

In the following section, the geometric and support details of the bridge, and the nonlinear material properties are briefly described to establish the context in which the subsequent analyses are performed. This is followed by the presentation of the results of a modal analysis and a discussion of the seismic actions that are subsequently considered. These actions consist of: (1) six benchmark records, three that are deemed to be far-field records and three with near-field characteristics and (2) seven natural records whose average spectrum matches the Type I Eurocode 8 design spectrum [20]. Incremental dynamic analysis is performed to explore the nonlinear seismic behaviour of different UD-CSB subjected to the benchmark ground motions, obtaining conclusions about the effect on the response of several design options: type of supports, number of struts and cable arrangement. Finally, the design of the bridge is verified under Eurocode 8 compliant accelerograms, comparing the recorded seismic demand in the time-domain with the capacity of each section along the deck.

\section{DEFINITION OF THE CONSIDERED STRUCTURES}

Various $80 \mathrm{~m}$ single-span UD-CSB were considered with two or multiple (15) diverting struts along the deck. The considered bridges have elevations that are shown in Figure 1, although different configurations for the bearings were analysed for each case. Both concentrated and expanded transverse cable arrangements were studied in this work to cover current trends in design. Figure 2 presents schematic illustrations of these configurations. The connection between the struts and the deck completely releases the rotation about the transverse axis $(Y)$ (see Figure 2), and the axial load 


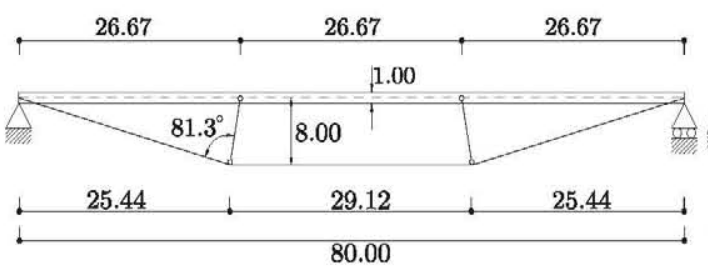

(a)

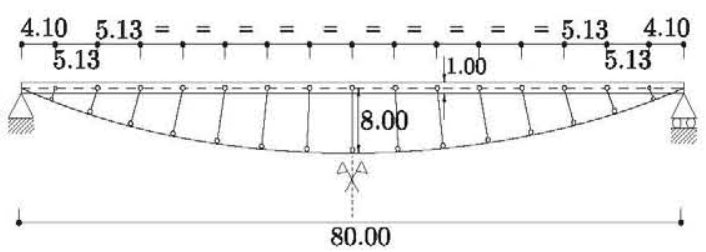

(b)

Figure 1. Elevation of UD-CSB for the models with: (a) two diverting struts and (b) multiple (15) diverting struts. Units in metres.

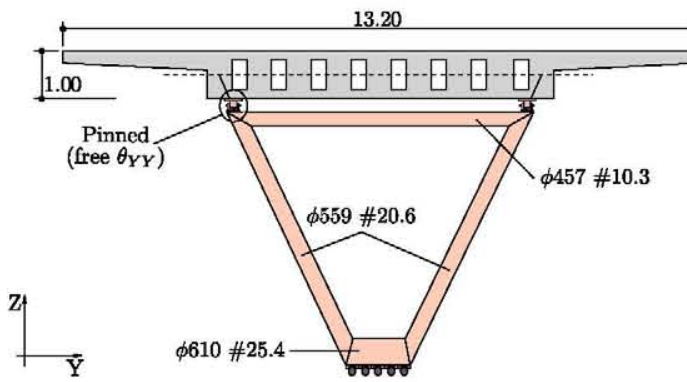

(a)

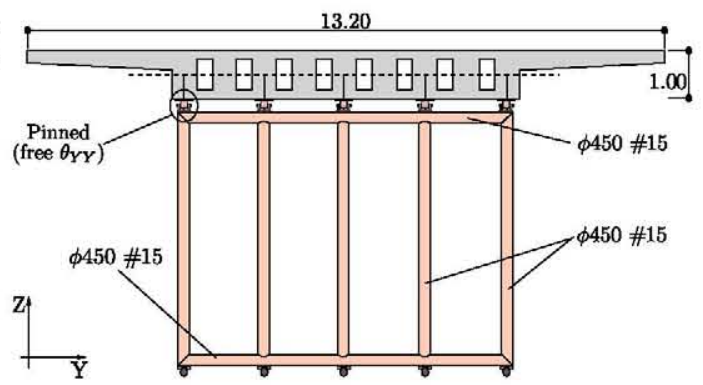

(b)

Figure 2. Schematic cross-section of the considered UD-CSB, where $\phi$ is the diameter and \# is the thickness of the metallic struts. (a) Concentrated diverting struts and (b) expanded diverting struts. Units of the deck in metres and units of steel struts in millimetres.

exerted by the cable-system and transferred through the compressed struts is directly introduced at the centroid of the deck to avoid local bending.

Two support conditions were explored: laminated elastomeric bearings (LEBs) and pot bearings (POT). After the design process followed by Ruiz-Teran and Aparicio [8], three LEBs were disposed per abutment with dimensions of $500 \times 600 \times 70 \mathrm{~mm}$. The stiffness of the LEB was represented in the model by means of linear springs along each principal direction. On the other hand, the POT bearings completely restrain, or release, particular horizontal movements. Two schemes, depicted in Figure 3, were considered: (a) the 'classical' layout [21], with two

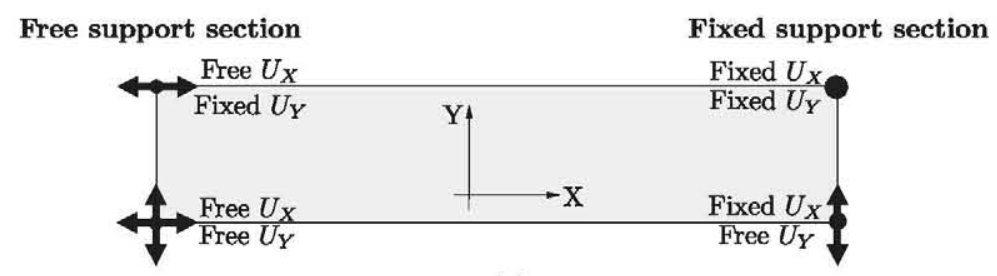

(a)

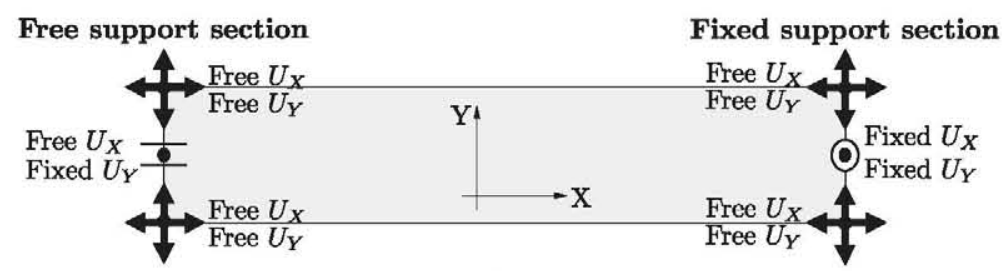

(b)

Figure 3. Plan view of the support configuration with different POT bearing schemes, including longitudinally free and fixed support sections in the abutments. (a) 'Classical' layout and (b) statically determinate layout. 
longitudinally restrained POT bearings, which prevent the transverse lateral rotation of the deck and consequently induce lateral bending moments in the deck at the fixed support section and (b) the statically determinate layout, which has been recommended for bridges with large horizontal actions because of wind load [21]. In this second scheme, the POT bearings only transfer vertical loading. The lateral horizontal loads are transferred by means of male-female deck-abutment connectors with a set of two POT bearings located in the vertical plane. The longitudinal load can be transferred either by replicating the aforementioned system in the longitudinal direction or by prestressing the deck to the abutment after placing one intermediate POT bearing in the vertical plane.

Table I summarizes the models considered in the present study that result from the combinations of the design choices just discussed. Table I also includes keywords (or reference tags) that are used hereafter when referring to the various models within the text.

Rigorous finite element models were developed. Because UD-CSB are very slender and lightweight structures, the proper mass distribution is a key factor in their dynamic analysis and shell elements were therefore adopted for modelling the deck. The mass superposition at the intersections of the webs and the slabs is avoided by means of proper offsets of the plane representing the shell [22]. Passive and active reinforcement was explicitly defined along the deck. Tied connections between active tendons and concrete webs were defined to represent the bond between the prestressed reinforcement and the deck. Conventional beam and truss elements were employed to define the struts and cable-system, respectively. Figure 4 illustrates the placement of active and passive reinforcement inside the deck. The prestressed tendons in bridges with two struts follows the typical layout adopted in continuous bridges, considering the connection with the struts as being similar to intermediate piers, where: (1) at the section where the deck is connected to the struts, the active reinforcement needs to be displaced above the centroid to cancel tensile stresses in the intrados and (2) at intermediate sections between the abutments and the struts, and between the struts, the active reinforcement is located below the centroid. The path of the active reinforcement in the model with multiple struts is a simple parabolic profile, typical of simply-supported bridges without stay-cables. This ensures that the active tendons are always below the centroid of the deck and maximizes the eccentricity at midspan. Additional masses representing both the pavement and the parapets have been included in the model.

Table I. Summary of employed UD-CSB configurations. Note that 'LEB' stands for laminated elastomeric bearing; 'POT' corresponds to POT bearings with a classical layout (Figure 3(a)); 'POT-b' denotes the use of POT bearings with a statically determinate configuration (Figure 3(b)).

\begin{tabular}{lccl}
\hline Keyword & Number of struts & Transverse arrangement & \multicolumn{1}{c}{ Bearings } \\
\hline BI-CONC-LEB & 2 & Concentrated & LEB \\
BI-CONC-POT & 2 & Concentrated & POT - Classical layout (Scheme a) \\
BI-CONC-POT-b & 2 & Concentrated & POT - Statically determinate layout (Scheme b) \\
BI-EXP-POT & 2 & Expanded & POT - Classical layout (Scheme a) \\
MULT-EXP-POT & 15 & Expanded & POT - Classical layout (Scheme a) \\
\hline
\end{tabular}

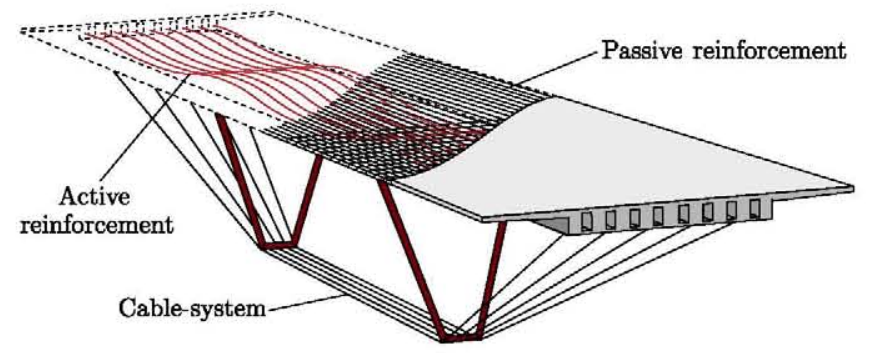

Figure 4. Three-dimensional free cut in UD-CSB with two struts, highlighting the passive and active steel in the model, besides the cable-system. 
A sensitivity analysis on the effect of Rayleigh damping on the seismic response of these structures was carried out. The same distribution of damping is considered for all the studied models in light of the moderate influence of this variable. This distribution was obtained by imposing a damping ratio of $5 \%$ in the fundamental mode of the most flexible model and a limit at a maximum frequency of $20 \mathrm{~Hz}$. Modes with higher vibration frequencies are deemed to have negligible contributions to the seismic response of UD-CSB, in agreement with Refs. [22, 23].

Relevant Eurocodes were considered to define the linear and nonlinear constitutive relations of the employed materials. Note that the following convention is employed throughout this work (for deformations or axial loads): a negative sign refers to compression, while a positive sign denotes tension. The concrete in the deck has a characteristic strength $\left(f_{\mathrm{ck}}\right)$ of $40 \mathrm{MPa}$ for the two-strut model and $35 \mathrm{MPa}$ for the multiple strut model. The model of the concrete includes softening when the normal compressive strain exceeds $\varepsilon_{\mathrm{c}, \mathrm{y}}=-0.1 \%$ and tension-stiffening, which has been defined through the widely used model of Mazars and Pijaudier-Cabot [24] to simulate cracking along the deck; the stress and strain corresponding to crack initiation are $f_{\mathrm{c}, \text { crack }}=3.5 \mathrm{MPa}$ and $\varepsilon_{\mathrm{c}, \text { crack }}=0.01 \%$, respectively, whereas the contribution of the concrete is considered null beyond $\varepsilon=0.035 \%$. Furthermore, the concrete considers the damage because of cyclic loading, defined through the reduction of the elastic modulus in terms of a scalar degradation variable $d$ as $E_{\mathrm{c}}=(1-d) E_{\mathrm{c}, 0}$, where $E_{\mathrm{c}, 0}=35 \mathrm{GPa}$ is the initial elastic modulus of the concrete [25] and $d$ is linearly interpolated depending on the normal deformation $\varepsilon$, assuming the values $d=0.5$ if $\varepsilon_{c, u}=-0.35 \%$ (the ultimate compression limit of the concrete) and $d=0.9$ if $\varepsilon=0.035 \%$ (the ultimate tension limit of the concrete). The steel representing passive reinforcement and diverting struts is B-500 SD (elasticity modulus $E_{\mathrm{s}}=210 \mathrm{GPa}$ ) and the model is set to capture yielding when the strain reaches $\varepsilon_{\mathrm{s}, \mathrm{y}}=0.24 \%$ $\left(f_{\mathrm{s}, \mathrm{y}}=500 \mathrm{MPa}\right)$. Subsequently, the transformations associated to its yielding surface because of kinematic cyclic loading, incorporating phenomena like the Bauschinger effect, are included. For the two-strut bridge, the tendons (of the internal prestressing) are comprised of 190 strands, each of area $140 \mathrm{~mm}^{2}$, while for the multiple-strut bridge just 60 such strands are employed. In the two-strut bridge, the five stay cables (cable-system below the deck) contain a total of 258 strands of $140 \mathrm{~mm}^{2}$ area, whereas in the multiple-strut case the five cables contain 264 of these strands. For both the tendons and the stay cables, the ultimate strength is $1860 \mathrm{MPa}$, the yield stress is $1770 \mathrm{MPa}$ and Young's modulus is $190 \mathrm{GPa}$. The struts, whose dimensions are shown in Figure 2, are made of steel and have a yield stress of $355 \mathrm{MPa}$ and a Young's modulus of $210 \mathrm{GPa}$.

\section{MODAL ANALYSIS AND NUMERICAL INTEGRATION SCHEME}

Nonlinear response history analysis (NL-RHA) has been selected here as the most rigorous method to model the behaviour of the bridges under earthquake excitation, fully taking into account material and geometric nonlinearities in the time domain.

The following loading scheme has been applied in accordance with the recommended procedure in conventional cable-stayed bridges [26]: (1) prestress in the active tendons and the cable-system is imposed; (2) following Eurocode 8 [20] provisions, the self-weight of the structure, the superimposed dead-load and the quasi-permanent live-load (20\% of the traffic live-load) is applied - thus ensuring that the equilibrated deformed state because of initial stresses is achieved prior to undertaking the dynamic analyses; (3) starting from the deformed state, vibration modes are extracted; (4) triaxial accelerograms are imposed at the supports, and the equation of motion is solved using the Hilber-Hughes-Taylor algorithm [27]; and (5) the results are post-processed, integrating the stress across each section to obtain the resultant internal forces and extracting the extreme response from the time domain variables.

Despite the seismic analysis of UD-CSB in this work being carried out by means of NL-RHA, which does not require the undertaking of modal decomposition, it is advantageous to initially perform modal analysis to shed some light on the fundamental linear dynamic characteristics of the structure. Figure 5 presents the fundamental mode of the bridge with two concentrated struts and LEB or POT bearings (adopting the classical layout), whereas Table II collects the vibration periods and the description of the fundamental modes in all the studied structures. 


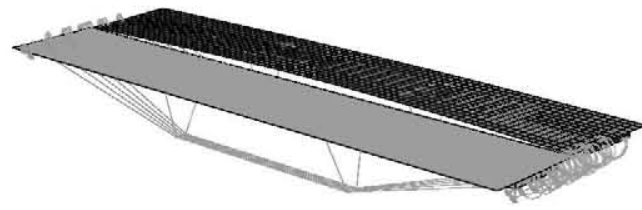

$z_{x}$

(a)

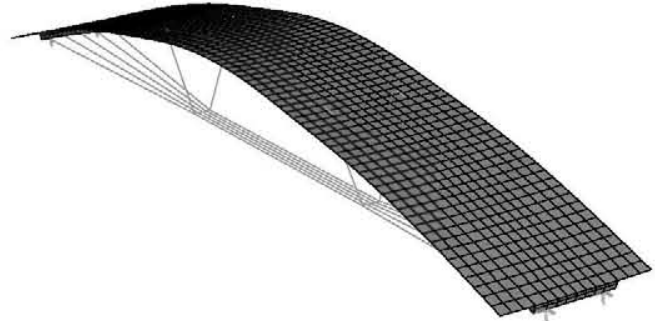

(b)

Figure 5. Fundamental vibration modes in models with different support conditions. (a) Model with LEB: transverse rigid body displacement. $T_{1}=1.43 \mathrm{~s}$; (b) model with POT, classical layout: first-order vertical flexure of the deck. $T_{1}=1.28 \mathrm{~s}$.

Table II. Fundamental vibration modes in the proposed structures. In each case, the description that is provided corresponds to the first mode of this type, for example, the first torsional deck mode for BI-CONCLEB is the $6^{\text {th }}$ overall mode and is designated as 'Deck torsion'.

\begin{tabular}{lccl}
\hline Structure & Mode No. & Period; $T$ [s] & \multicolumn{1}{c}{ Description } \\
\hline BI-CONC-LEB & 1 & 1.43 & Transverse rigid body motion \\
& 2 & 1.37 & Longitudinal rigid body motion \\
& 3 & 1.28 & Vertical deck flexure \\
BI-CONC-POT & 6 & 0.57 & Deck torsion \\
& 11 & 0.18 & Transverse deck flexure \\
BI-CONC-POT-b & 1 & 1.28 & Vertical deck flexure \\
& 3 & 0.57 & Deck torsion \\
BI-EXP-POT & 5 & 0.36 & Transverse deck flexure \\
& 1 & 1.28 & Vertical deck flexure \\
MULT-EXP-POT & 3 & 0.57 & Deck torsion \\
& 5 & 0.41 & Transverse deck flexure \\
& 1 & 1.28 & Vertical deck flexure \\
& 3 & 0.58 & Deck torsion \\
& 5 & 0.36 & Transverse deck flexure \\
& 1 & 1.33 & Vertical deck flexure \\
& 3 & 0.61 & Deck torsion \\
\end{tabular}

Although the first vertical flexural mode in the model with multiple struts has a period (1.33 s) that is slightly longer than that obtained in the equivalent bridge with two struts $(1.28 \mathrm{~s})$, because of the additional mass associated with the larger number of struts, the modes are otherwise only weakly influenced by the number of struts. However, vibration properties, and hence dynamic response, are strongly affected by the type of bearings used [4]. As can be observed in Figure 5, the model with LEB presents rigid-body motions in the first two modes along the transverse and longitudinal directions with $T_{1 T}=1.43 \mathrm{~s}$ (Figure $5(\mathrm{a})$ ) and $T_{1 L}=1.37 \mathrm{~s}$, respectively. Such deformations isolate the structure, increasing total displacements but notably reducing the seismic demand associated with relative displacements and, therefore, the internal forces. Vertical modes are similar in models with LEB or POT bearings, regardless of their layout in plan, because the vertical stiffness of both supports is very high. The first transverse period in UD-CSB with POT bearings is lengthened if Scheme $\mathrm{b}$ is adopted; the other fundamental periods remain unchanged. Finally, the negligible effect of the transverse cable-arrangement on modal properties has been verified (only torsional frequencies are slightly affected). 


\section{SEISMIC ACTION}

\subsection{Benchmark records}

In this work, six accelerograms commonly used as 'reference' far-field and near-field records by the earthquake engineering community have been considered. The far-field records correspond to the El Centro recording of the 1940 Imperial Valley earthquake, the El Monte-Fairview recording of the 1994 Northridge earthquake, and the Riverside airport record from the 1992 Landers earthquake. On the other hand, the selected near-field ground motions with pulse-like effects are the Pacoima Dam recording (upper-left abutment) of the 1971 San Fernando earthquake, the El Centro recording from the 1979 Imperial Valley earthquake and the Takatori record from the 1995 Kobe earthquake. All of the records have been scaled, using the same factor $(k)$ for all three components to ensure a significant nonlinear response. To reduce the computational cost of the time-demanding NL-RHA, only the strong-shaking phase of the records is considered. The duration of the strong motion is often defined as the interval between the $5^{\text {th }}$ and $75^{\text {th }}$ or $95^{\text {th }}$ percentile of the cumulative Husid Plot [28]. In this study, the time-history analyses are conducted to include the longer of these windows, and the portions of the records from the $0^{\text {th }}$ to the $95^{\text {th }}$ percentile are considered; these significant durations have been obtained for each of the three components for each of the records employed in this study. The longest of the three components is used to define the length of the analysis for each record. This approach yields an excitation duration of 30,28 and $36 \mathrm{~s}$, respectively, for the El Centro 1940, El Monte and Riverside far-field signals, while the duration is 12,12 and $16 \mathrm{~s}$, respectively, for Pacoima Dam, El Centro 1979 and Takatori near-field records.

Figure 6 depicts the original benchmark triaxial spectra (without scaling, $k=1$ ), highlighting the first and second vertical vibration modes of the structure, and the first transverse and longitudinal modes with deformation of the deck (i.e., excluding rigid body motion modes), which have significant contributions in the response (note the different ordinate range in Figure 6, which highlights the greater intensity of near-field signals).

\subsection{Eurocode 8 natural accelerograms}

To avoid the loss of generality associated with prescribing the seismic actions for a specific location, we specify a design (the 475-year motion) peak ground acceleration of $a_{\mathrm{g}}=0.4 \mathrm{~g}$ that is broadly representative of highly-seismic regions. The ground conditions are assumed to be rock (Type A according to Eurocode 8).

Eurocode 8 [20] proposes the use of a set of natural accelerograms (three or more) whose average acceleration spectrum fits the target design spectrum in the range of periods: $\left[0.2 T_{1}, 2 T_{1}\right]$, with $T_{1}$ being the fundamental period in the vertical or horizontal direction, depending upon the mode. The average spectrum should be above $90 \%$ of the target over the entire range. Because of the large PGA being considered $(0.4 g)$ and the unrealistic shape of the design spectrum, combinations of unscaled natural accelerograms are extremely difficult to find if one desires a match to both the horizontal and, especially, vertical spectra. Therefore, scaling factors have been considered, employing the same factor for all three components of the record. An ad hoc search algorithm has been used to identify appropriate signals from within the Pacific Earthquake Engineering Research Center-National Ground Acceleration (PEER-NGA) and the European Strong-Motion Databases. Figure 7 illustrates the horizontal and vertical target spectra and the spectra of the scaled natural records.

The largest scale factor that has been employed is 5.23, while the arithmetic mean of the factors is 2.45. Hence, the process of scaling should avoid the introduction of potential biases in the results [29]. These factors are shown in Table III, where the main seismological features of the selected records are also presented. No attempt has been made to distinguish between magnitude, near-field effects or soil class among the selected records. On the other hand, all selected signals are from earthquakes with magnitude $M_{\mathrm{w}}<7$, and hence they are consistent with the Type 1 spectrum defined by Eurocode 8 . In Table III, 'ID' is the keyword used for the presentation of the results in Section 7 and is also the 'Record Sequence Number' from the PEER-NGA database. Note that although the $V_{\mathrm{s}, 30}$ values of these records are not consistent with Type A ground conditions, we are generally only interested in 

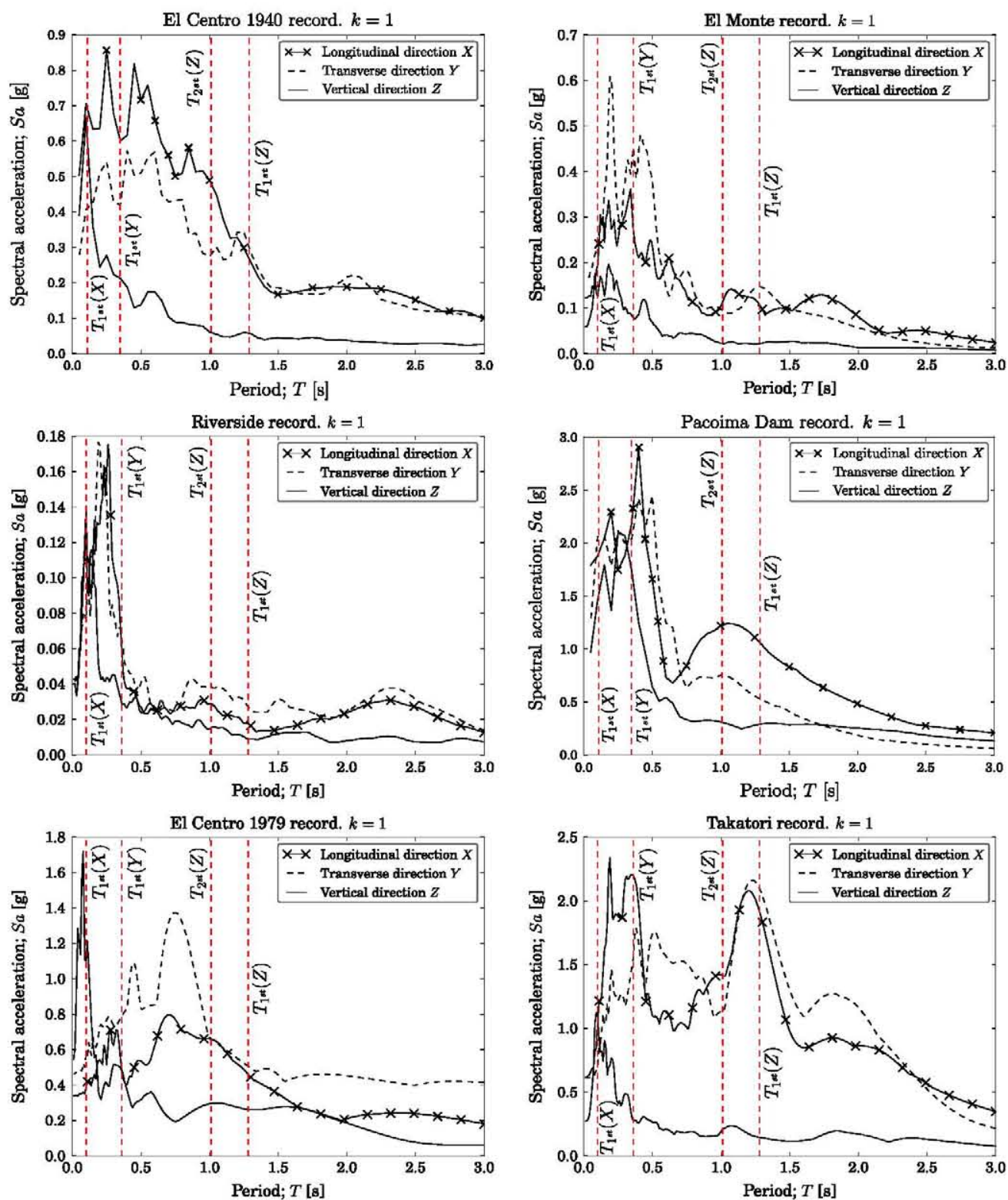

Figure 6. Longitudinal $(X)$, transverse $(Y)$ and vertical $(Z)$ spectra of the unscaled $(\boldsymbol{k}=\mathbf{1})$ benchmark records. The most important vibration periods of the model with two expanded struts and POT supports (Scheme a) are also represented with different vertical dashed lines. The other typologies are not included as the first modes are similar.

soil conditions because they influence spectral shape. Given that the selected records do a good job of matching the target spectra, their $V_{\mathrm{s}, 30}$ values are of little consequence.

\section{PROPOSED SEISMIC INTENSITY MEASURE: SPECTRAL POWER INDEX}

To compare the structural response from signals as different as the benchmark records employed in this study, it is necessary to employ an appropriate IM aiming to reduce the dispersion of the response estimates.

In the present work, the classical IM based on the spectral acceleration corresponding to the elastic fundamental period, $S_{\mathrm{a}}\left(T_{1}\right)$, is inadequate for the analysis of UD-CSB because of important highermode contributions. This is especially the case for models with POT bearings because of the 


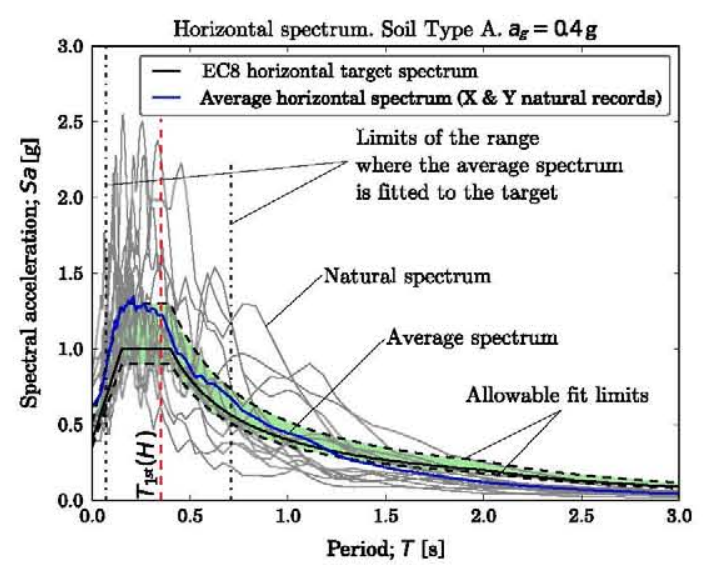

(a)

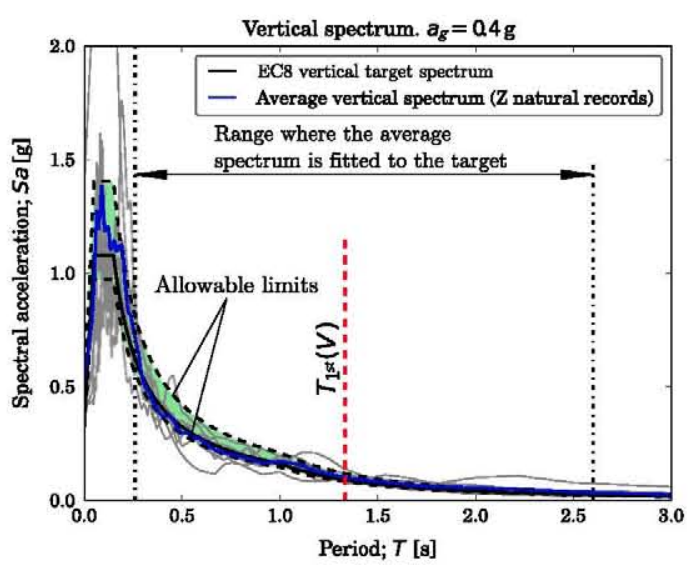

(b)

Figure 7. Fit of natural accelerograms spectra to the target Eurocode 8 action, besides the fundamental periods $\left(T_{1}(H)\right.$ and $T_{1}(V)$ for horizontal and vertical modes, regardless the bridge typology) and acceptability intervals in the range of interesting modes. (a) Horizontal spectra and (b) vertical spectra.

Table III. Seismological information for the natural records employed to verify the models according with Eurocode 8. The column 'ID' corresponds to the record sequence number from the PEER-NGA database, $M_{\mathrm{w}}$ denotes moment magnitude, $R_{\mathrm{epi}}$ is the epicentral distance, $V_{\mathrm{s}, 30}$ is the average shear-wave velocity over the uppermost $30 \mathrm{~m}, D_{0-100 \%}$ is the original duration, $D_{0-95} \%$ is the reduced duration and $k$ is the scale

factor. For $M_{\mathrm{w}}, R_{\text {epi }}$ and $k$, the arithmetic mean is presented as the 'average', while for the remaining columns the geometric mean is used.

\begin{tabular}{lcccccrr}
\hline Earthquake & ID & $M_{\mathrm{w}}$ & $R_{\text {epi }}[\mathrm{km}]$ & $V_{s, 30}[\mathrm{~m} / \mathrm{s}]$ & $D_{0-100 \%}[\mathrm{~s}]$ & $D_{0-95 \%}[\mathrm{~s}]$ & $k$ \\
\hline Coyote Lake, USA & 147 & 5.7 & 11 & 271 & 26.86 & 10.13 & 2.32 \\
Victoria, Mexico & 265 & 6.3 & 34 & 660 & 24.45 & 12.69 & 1.36 \\
Coalinga, USA & 410 & 5.8 & 11 & 376 & 21.58 & 9.77 & 1.89 \\
Morgan Hill, USA & 456 & 6.2 & 38 & 271 & 29.98 & 18.15 & 2.40 \\
Northridge, USA & 952 & 6.7 & 17 & 546 & 23.98 & 10.87 & 1.21 \\
Northridge, USA & 996 & 6.7 & 17 & 255 & 29.99 & 14.14 & 2.80 \\
Chi-Chi, Taiwan & 2383 & 5.9 & 34 & 434 & 62.00 & 14.81 & 5.23 \\
Average & & $\mathbf{6 . 2}$ & $\mathbf{2 3}$ & $\mathbf{3 7 8}$ & $\mathbf{2 9 . 3 9}$ & $\mathbf{1 2 . 6 5}$ & $\mathbf{2 . 4 5}$ \\
\hline
\end{tabular}

significant contribution of longitudinal, transverse and vertical responses, and can be appreciated from the different horizontal and vertical period ranges shown in Figure 7. Moreover, important period elongations caused by material damage may occur during strong shaking. Again, this is especially important in models with POT bearings, because the first modes involve relative deformation along the deck (see Section 3). In addition, the 'peak and trough' nature of natural spectra gives importance to small variations in the vibration period (see Figure 6), which could arise because of the development of material nonlinearities during the shaking. This effect also changes the spectra through the modification of damping. Therefore, scaling the spectra to adjust the mean spectrum only according to a specific mode may be inefficient because the response depends on several excitation directions and modes, which may be modified in turn.

Continuing the research line established by [18, 19], an IM called SPI (spectral power index) is proposed here to take into account the triaxial spectral acceleration associated with the most important periods of the structure, and the importance of each of the dominant modes in the global response of the bridge along the respective direction. The importance of each $n$-mode in the response of the bridge in direction $j(j=X, Y, Z)$ is represented by means of its modal participation factor $\Gamma_{n}^{j}$, obtained according to Equation (1). 


$$
\Gamma_{n}^{j}=\frac{\phi_{n}^{T} \mathbf{m} t^{j}}{M_{n}} ; \quad \text { with } j=X, Y, Z
$$

Here, $\phi_{n}$ and $M_{n}$ are respectively the mode shape and mass associated with the $n^{\text {th }}$ vibration mode; $t^{j}$ is the displacement vector of the structure when a static application of a unit motion is imposed along the axis $j$, either a translation or a rotation [23].

The proposed parameter combines the participation factor in a specific mode and direction with the seismic action introduced in that direction, which is represented by means of the corresponding spectral acceleration $\left(S_{\mathbf{a}}{ }^{j}\left(T_{n}\right)\right.$ with $\left.j=X, Y, Z\right)$. The product of both values is repeated in all modes with frequency lower than $f_{\text {last }}=20 \mathrm{~Hz}$, and finally all the results are combined to obtain the proposed SPI. The SPI is then defined as in Equation (2), in which $j=X, Y, Z$ and $N_{\text {modes }}$ is the number of the last mode required to achieve the frequency limit $f_{\text {last }}=20 \mathrm{~Hz}$.

$$
\mathrm{SPT}^{j}=\sum_{n=1}^{N_{\text {modes }}} S_{\mathbf{a}}^{j}\left(T_{n}\right) \hat{\Gamma}_{n}^{j}
$$

It is important to note that the participation factor $\Gamma_{n}^{j}$, associated with the translation in one specific direction $j$, is zero if the corresponding $n^{\text {th }}$ mode is purely antisymmetric, because the displacement of each node is counteracted by an equal and opposite displacement in the antisymmetric node referenced with respect to the gravity centre of the whole model. Therefore, if $\Gamma_{n}^{U X}, \Gamma_{n}^{U Y}$ and $\Gamma_{n}^{U Z}$ (the participation factors associated with the translations) are considered directly in SPI (ignoring the rotations), the contribution of these modes would be neglected, but their participation in the overall response is presumably significant in light of the spectral acceleration associated with periods $T_{2}(Z)$ in Figure 6 (with antisymmetric vertical flexure of the deck). To overcome this problem, the participation factors associated with the rotational degrees of freedom $\Gamma_{n}^{U R X}, \Gamma_{n}^{U R Y}$ and $\Gamma_{n}^{U R Z}$ in each mode are also considered, employing the following modified participation factors in each direction $\hat{\Gamma}_{n}^{j}$ :

$$
\begin{gathered}
\hat{\Gamma}_{n}^{X}=\frac{\left|\Gamma_{n}^{U X}\right|}{\max _{n}\left(\left|\Gamma_{n}^{U X}\right|\right)} \\
\hat{\Gamma}_{n}^{Y}=\frac{\left|\Gamma_{n}^{U Y}\right|}{\max _{n}\left(\left|\Gamma_{n}^{U Y}\right|\right)}+\frac{\left|\Gamma_{n}^{U R Z}\right|}{\max _{n}\left(\left|\Gamma_{n}^{U R Z}\right|\right)} \\
\hat{\Gamma}_{n}^{Z}=\frac{\left|\Gamma_{n}^{U Z}\right|}{\max _{n}\left(\left|\Gamma_{n}^{U Z}\right|\right)}+\frac{\left|\Gamma_{n}^{U R Y}\right|}{\max _{n}\left(\left|\Gamma_{n}^{U R Y}\right|\right)}
\end{gathered}
$$

It should be highlighted that the rotation about the transverse axis ' $Y$ ', which crosses the gravity centre of the whole model causes vertical movements, and therefore it has contribution in the modified vertical participation factor $\left(\hat{\Gamma}_{n}^{Z}\right)$; the same could be said for the rotation about the vertical axis ' $Z$ ', participating in the transverse displacements and hence to $\hat{\Gamma}_{n}^{Y}$. However, no rotation about any principal axis crossing the gravity centre of the model contributes significantly to the longitudinal displacements. This has been taken into account in expression (3) by not including a second term in the expression for $\hat{\Gamma}_{n}^{X}$. The participation factors, both applied to translations or rotations, are normalized before being aggregated in this equation. This is conducted because those related with the rotations are significantly higher and would otherwise dominate the results. 
The values of SPI found for the considered models when subjected to the unscaled benchmark records are presented in Table IV. The results here refer to the elastic modal vibration properties, and the spectral acceleration values also correspond to the elastic spectra. Hence, no attempt has been made to consider the period elongation or the effect of hysteretic damping in the formulation of the SPI. The analysis is thus valid for the structure just after the application of its self-weight, live loads and prestress (when the material characteristics of the structure remain linear). Several conclusions may be extracted in light of the SPI results shown in Table IV:

(i) The bridge with LEB is effectively isolated from the seismic energy in the horizontal plane, especially in the longitudinal direction. For bridges with this configuration, the excitation in the vertical direction is most important (which is in keeping with our intuition). The seismic demand associated with bridges using POT bearings, regardless of their layout, is clearly far in excess of those using LEB when considering horizontal excitations. However, the SPI in the vertical direction remains essentially constant because the stiffness of both the LEB and the POT bearings in the vertical directions is very high. One would often presume that nearfield records would exert greater demand than far-field signals. However, for bridges with LEB this is not the case once both records are scaled to the same SPI. The reason for this is that the velocity pulse in the near-field records employed only appears in the horizontal plane and not in the vertical direction (see Figure 6). Because the vertical direction clearly dominates the overall SPI for bridges with LEB, horizontal pulse-like effects that may be associated with

Table IV. SPI values for the original benchmark records $(\boldsymbol{k}=\mathbf{1})$ applied to the different models along the three principal directions; longitudinal $\left(\mathrm{SPI}^{\boldsymbol{X}}\right)$, transverse $\left(\mathrm{SPI}^{\mathbf{Y}}\right)$ and vertical $\left(\mathrm{SPI}^{Z}\right)$. Also shown is their average value (arithmetic mean).

\begin{tabular}{|c|c|c|c|c|c|}
\hline Record & Structure & $\operatorname{SPI}^{X}$ & $\mathrm{SPI}^{Y}$ & $\mathrm{SPI}^{Z}$ & Average \\
\hline \multicolumn{6}{|c|}{ Far-field recordings } \\
\hline \multirow[t]{5}{*}{ El Centro 1940} & BI-CONC-LEB & 2.3 & 8.8 & 28.3 & 13.1 \\
\hline & BI-CONC-POT & 27.9 & 30.5 & 30.1 & 29.5 \\
\hline & BI-CONC-POT-b & 28.0 & 31.4 & 29.2 & 29.5 \\
\hline & BI-EXP-POT & 29.1 & 31.2 & 30.4 & 30.2 \\
\hline & MULT-EXP-POT & 28.0 & 38.2 & 31.4 & 32.5 \\
\hline \multirow[t]{5}{*}{ El Monte } & BI-CONC-LEB & 1.0 & 4.5 & 10.1 & 5.2 \\
\hline & BI-CONC-POT & 11.4 & 35.7 & 10.5 & 19.2 \\
\hline & BI-CONC-POT-b & 10.2 & 26.2 & 10.1 & 15.5 \\
\hline & BI-EXP-POT & 11.9 & 30.8 & 10.7 & 17.8 \\
\hline & MULT-EXP-POT & 11.3 & 37.6 & 11.3 & 20.0 \\
\hline \multirow[t]{5}{*}{ Riverside } & BI-CONC-LEB & 0.2 & 1.1 & 5.9 & 2.4 \\
\hline & BI-CONC-POT & 5.3 & 9.4 & 6.2 & 7.0 \\
\hline & BI-CONC-POT-b & 3.9 & 5.8 & 5.9 & 5.2 \\
\hline & BI-EXP-POT & 5.5 & 8.1 & 6.3 & 6.6 \\
\hline & MULT-EXP-POT & 4.8 & 10.3 & 6.6 & 7.2 \\
\hline \multicolumn{6}{|c|}{ Near-field recordings } \\
\hline Record & Structure & $\operatorname{SPI}^{X}$ & $\mathrm{SPI}^{Y}$ & $\mathrm{SPI}^{Z}$ & Average \\
\hline \multirow[t]{5}{*}{ Pacoima Dam } & BI-CONC-LEB & 10.1 & 20.1 & 82.7 & 37.6 \\
\hline & BI-CONC-POT & 83.9 & 165.5 & 85.4 & 111.6 \\
\hline & BI-CONC-POT-b & 84.1 & 167.4 & 83.1 & 111.5 \\
\hline & BI-EXP-POT & 87.3 & 174.1 & 85.9 & 115.8 \\
\hline & MULT-EXP-POT & 79.2 & 213.6 & 87.7 & 126.8 \\
\hline \multirow[t]{5}{*}{ El Centro 1979} & BI-CONC-LEB & 4.4 & 12.9 & 48.6 & 22.0 \\
\hline & BI-CONC-POT & 23.8 & 46.1 & 50.2 & 40.0 \\
\hline & BI-CONC-POT-b & 18.8 & 34.1 & 46.9 & 33.3 \\
\hline & BI-EXP-POT & 24.8 & 38.2 & 50.2 & 37.7 \\
\hline & MULT-EXP-POT & 22.5 & 50.4 & 54.2 & 42.4 \\
\hline \multirow[t]{5}{*}{ Takatori } & BI-CONC-LEB & 15.4 & 46.9 & 51.7 & 38.0 \\
\hline & BI-CONC-POT & 58.5 & 121.5 & 55.2 & 78.4 \\
\hline & BI-CONC-POT-b & 48.7 & 91.3 & 52.5 & 64.2 \\
\hline & BI-EXP-POT & 60.9 & 102.8 & 56.2 & 73.3 \\
\hline & MULT-EXP-POT & 52.0 & 128.7 & 57.3 & 79.3 \\
\hline
\end{tabular}


near-field events are of little consequence. The same cannot be said for bridges with POT bearings.

(ii) For the particular set of records considered here, the models with POT bearings are expected to be affected by greater seismic actions in the transverse direction than in longitudinal and vertical directions, in which similar values of SPI are obtained (except for the El Centro 1979 record). This effect, especially strong in the Pacoima Dam record in comparison with the El Centro 1940 signal, could be explained by means of the triaxial spectra of the benchmark records shown previously in Figure 6; the fundamental period in the transverse direction $\left(T_{1^{\mathrm{st}}}(Y)=0.36 \mathrm{~s}\right)$ is in the area with extreme spectral accelerations in the transverse component of the Pacoima Dam record, whereas this period seems to be located in a 'valley' of the corresponding El Centro 1940 spectrum.

(iii) The unscaled near-field records are much more demanding than the unscaled far-field records. Comparing the Pacoima Dam and the El Centro 1940 records, SPI factors are about four times higher in the former for all of the models. This, of course, is to be expected based upon the larger spectral accelerations shown in Figure 6. The differences in response reflect differences in spectral accelerations in general and are not attributed to any 'pulse-like' effects.

(iv) In most of the studied structures and records, SPI strongly depends on the direction considered, which needs to be selected depending on the response of interest, for example, the transverse factor $\left(\mathrm{SPI}^{Y}\right)$ should be applied to compare the transverse bending moment $\left(M_{z z}\right)$ along the deck for different records. Unlike the clear selection of SPI in forces associated with the transverse behaviour of UD-CSB, the significant coupling between the vertical and longitudinal response because of the cable-system (like in conventional cable-stayed bridges) may suggest the selection of an average factor between $\mathrm{SPI}^{Z}$ and $\mathrm{SPI}^{X}$ in the study of the axial load $(N)$ and vertical bending moments $\left(M_{y y}\right)$, which could lead to the greatest efficiency of the defined IM. However, the strong differences between $\mathrm{SPI}^{Z}$ and $\mathrm{SPI}^{X}$ discourages this solution in models with LEB supports. In light of the results obtained in the following section, it is suggested to consider $\mathrm{SPI}^{Z}$ for the comparison of vertical bending moments and $\mathrm{SPI}^{X}$ for the axial loads in all of the studied structures.

\section{NONLINEAR SEISMIC RESPONSE UNDER SCALED BENCHMARK RECORDS}

The response of UD-CSB in the nonlinear range is considered by performing incremental dynamic analysis with the benchmark triaxial records. The same scale factor $k$ is applied to each of the three components of each record and this scale factor is varied to sample the response over a broad range. It should be stated here that the objective is not to try to obtain a set of results that can be immediately used for other applications, the sample size is simply too small to achieve such an objective. Rather, the goal here is to consider a small set of records in detail and to try to understand the response of the bridge to each record from a fundamental perspective. Here we are not interested in the results obtained from the law of large numbers, but rather in understanding the dominant physical effects that enable one to anticipate the results of greater numbers of analyses. The detailed consideration of six benchmark records is sufficient for this purpose.

The key question to be addressed is: how does the vertical seismic response of the bridge evolve as the earthquake intensity is increased beyond the linear range? Figure 8 presents the extreme vertical bending moment recorded along the deck versus the extreme increment in the stress of the cablesystem for several models and scale factors. Nonlinear response starts when cracking in the deck arises. From this point, the vertical stiffness of the deck is reduced, whereas the cable-system (which remains elastic) assumes a greater role in providing resistance to the vertical demand. This explains the higher stress increments in the stays that are observed as the departure from linear response occurs. This behaviour could be foreseen based upon the reduction of the flexural stiffness of the deck [7] during the shaking. This characteristic response is satisfactory in terms of global performance of the structure, because the cable-system becomes more effective when the bridge faces an unexpectedly high seismic demand. The model with multiple struts spreads cracking along 


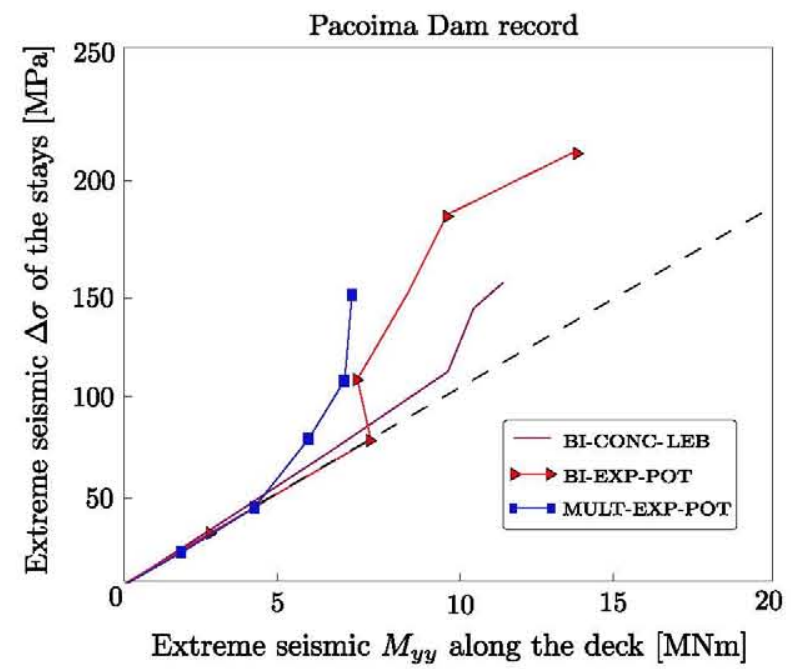

Figure 8. Maximum absolute stress variation in the cable-system span versus the extreme vertical bending moment along the deck for different amplification factors and bridge typologies. Results shown for the Pacoima Dam record using various scale factors.

the deck and the aforementioned behaviour is more uniform compared with the model including two struts and POT bearings, reducing the stress increment and thus the possibility of failure because of low-cycle fatigue. Despite the high seismic demand considered herein, the maximum allowable stress in the cable-stays has not been exceeded in any structure, for any record or for any scaling factor.

Figure 9 shows the extreme recorded bending moments (associated with vertical $M_{y y}$ and transverse flexure $M_{z z}$ ) and axial load $(N)$ due exclusively to the seismic actions along the deck (extracting the forces recorded at the initial deformed configuration from the total results) considering the original El Centro 1940 record $(k=1)$. The increment in the seismic demand because of the substitution of LEB by POT bearings is clear; the axial load is strongly increased in the right half of the deck, next to the fixed abutment (see Figure 3) because of the longitudinal constraint. This load is sufficient to decompress the initial preloaded state and consequently magnify cracking when considering the original Pacoima Dam (in this case the decompression is observed if $k>0.5$ ) and Takatori records, or when the El Centro 1940 record is scaled by a factor of $k>2$.

Bridges with two struts and POT bearings concentrate the vertical bending moment in the lateral spans which, when added to the axial load, propagates cracks in the centre of the lateral span towards the fixed end. The consequence could be the localization of damage in the centre of the right span under extreme seismic events, as may be appreciated from inspection of Figure 10, which shows the extreme relative vertical displacement in the deck for the El Centro 1940 record scaled by a factor of three. Such localization of demand, which would clearly be dangerous for the global safety of the bridge, is avoided in the model with multiple struts, because the vertical bending moment is reduced in the lateral spans (Figure 9(a)) and cracking is controlled.

The vertical seismic bending moment recorded in the deck at the fixed end (the right-hand-end according to Figure 3 ) is significant in models with POT bearings, especially given that the supports allow for rotation about the transverse axis $(Y)$. Cracking caused by seismically-induced axial load and transverse bending moment at this location (see Figures 9(c) and (b) respectively) is most likely the reason behind this effect as material nonlinearities move the effective centroid and, therefore, the prestressed tendons and cable-system anchors can introduce significant vertical bending moments in the deck at the fixed end.

As was expected, the influence on the seismic response of the POT layout is significant primarily in the transverse direction. Scheme 'a' leads to smaller transverse bending moments along the bridge because of the horizontal restraint, because it behaves like a fixed-pinned beam under lateral loads. On the other hand, Scheme ' $b$ ' behaves like a simply supported beam under lateral loads, notably increasing the transverse bending moment in the midspan (the increment is a factor of 1.77 , which is the ratio between the maximum bending moment in a pinned-pinned beam and that in a pinned-encastred beam). 


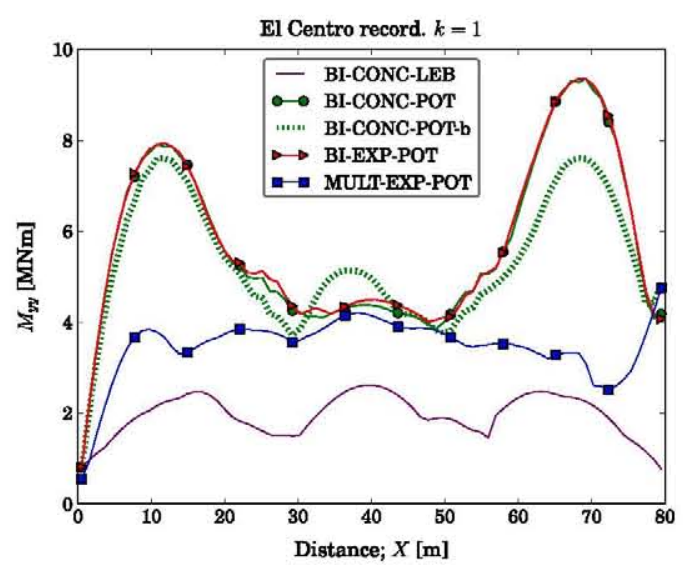

(a) Vertical bending moment $M_{y y}$

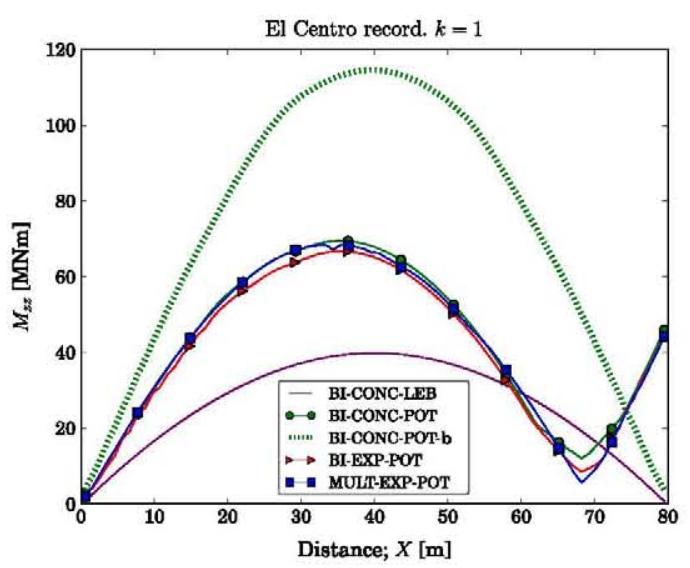

(b) Transverse bending moment $M_{z z}$

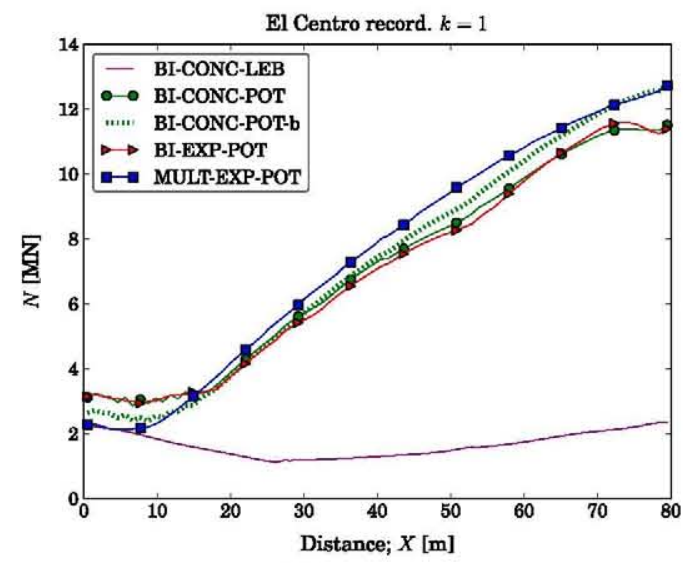

(c) Axial load $N$

Figure 9. Distribution of the extreme seismic bending moments [MNm] and axial loads [MN] along the deck considering different UD-CSB typologies. Results shown for the original El Centro 1940 record $(\boldsymbol{k}=\mathbf{1})$.

The seismic behaviour of these bridges is hardly influenced by the transverse cable arrangement, which is in agreement with the results obtained from the modal analysis presented in Section 3, and the SPI factors in Table IV. On the other hand, seismic analyses considering only one component of the accelerogram per analysis ( $\ddot{u}_{g}^{j}$, with $j=X, Y$ or $Z$ ) have been computed, verifying the coupling between the longitudinal and vertical responses because of the cable-system and concluding that the vertical component of the record is the most demanding one in UD-CSB because, if only the vertical component of the record is imposed $\left(\ddot{u}_{g}^{Z}\right)$, the nonlinear response starts with smaller values of the scale factor than if the other components are considered alone (especially the transverse component, $\ddot{u}_{g}^{Y}$ ).

\subsection{Energy balance: dissipation factor $\Omega$}

In addition to consideration of peak response metrics, the way the inelastic seismic demand along the deck is resisted during the earthquake by means of energy concepts was also investigated. This was achieved by comparing the energy dissipated through material hysteresis $\left(E_{\mathrm{Sp}}\right)$ and the energy lost by the damage of the elastic properties in the concrete because of cyclic response $\left(E_{\mathrm{Sd}}\right)$. The present study deals with complex structures and, consequently, the definition of the energy balance in continuum mechanics is required; a thorough description of the generalized terms representing each contribution to the energy balance may be found elsewhere [22]. We are only interested in the sources of energy dissipation of the system and the external work $\left(E_{\mathrm{W}}\right)$ introduced by the ground 


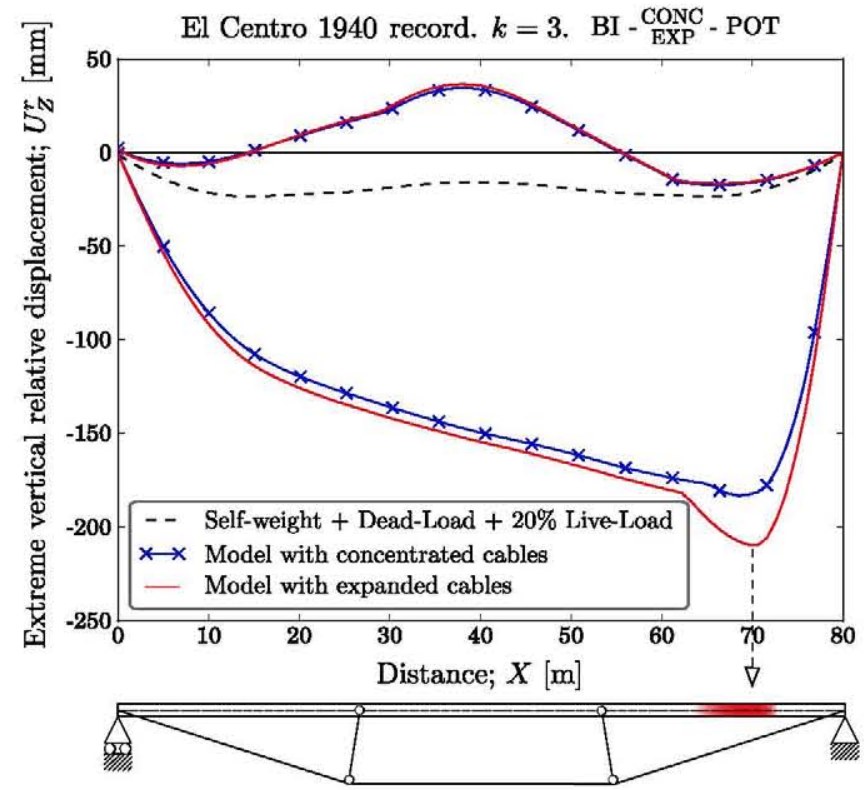

Figure 10. Extreme relative displacements because of seismic actions (plus self-weight, dead-loads and $20 \%$ of the live-load) in the vertical direction. Results are shown for models with two struts and POT bearings considering El Centro 1940 record scaled by a factor of $k=3$. The initial deformed configuration is represented with a dashed line, which is independent of the spatial cable assembly. The damage in the right span, close to the fixed abutment, is represented by red color in the schematic representation of the structure.

motion. The following damage ratio is introduced here, integrating the energy balance over the duration of the accelerogram to address the amount of the total seismic energy that is dissipated by plasticity and damage of the whole structure.

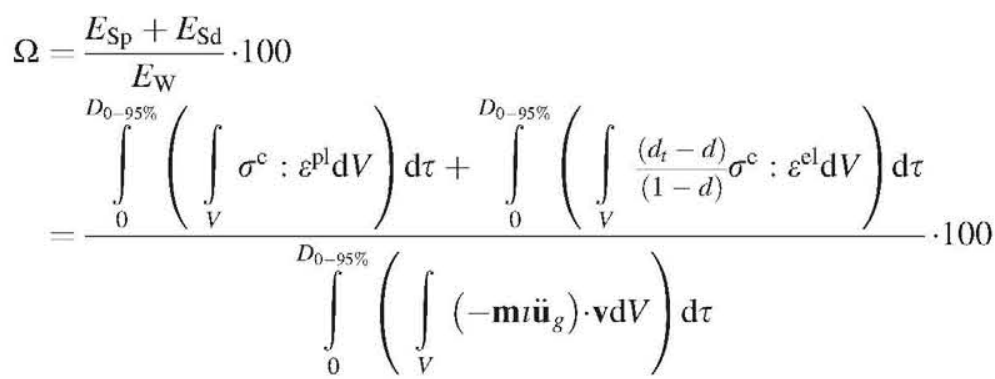

In Equation (4), $\int_{V}(\cdot) \mathrm{d} V$ represents the integral over the volume $V$ of the studied portion of the structure (in this study $V$ is the whole model, however, the deck is the only member of the bridge presenting nonlinear response); $\sigma^{\mathrm{c}}$ is the stress derived from the constitutive equation, without viscous dissipation effects included; $\varepsilon^{\mathrm{el}}$ and $\varepsilon^{\mathrm{pl}}$ are respectively the elastic and plastic strain rates; $D_{0-95 \%}$ is the reduced length of the accelerogram (defined earlier in Section 4); $d$ is the continuum damage parameter (scalar) defined in Section 2, which is assumed to remain fixed at the value attained at time $t\left(d_{t}\right)$ upon unloading. The remaining parameters, $\mathbf{m}$ and $t$ are respectively the mass matrix, the influence matrix connecting the degrees of freedom of the structure and imposed accelerogram directions $\mathbf{u}_{g}^{T}(t)=\left(\ddot{u}_{g}^{X}, \ddot{u}_{g}^{Y}, \ddot{u}_{g}^{Z}\right)$, where $\ddot{u}_{g}^{j}$ is the ground acceleration in $j$-direction ( $j=X, Y, Z$ in this study, see Figures 2 and 3 for the definition of the global coordinate system). The operator ' $:$ ' denotes the scalar product of two matrices, and ' $t$ ' matrix multiplication.

Table V presents a comparison of the aforementioned ratio for the original Pacoima Dam record in all of the studied structures. The strong increment in the seismic damage considering POT bearings 
Table V. Dissipation factor $(\boldsymbol{\Omega} \%)$ in all studied UD-CSB. Results are shown for the original Pacoima Dam record $(k=1)$.

\begin{tabular}{cccccc}
\hline & BI-CONC-LEB & BI-CONC-POT & BI-CONC-POT-b & BI-EXP-POT & MULT-EXP-POT \\
\hline$\Omega \%$ & 5.5 & 26.0 & 24.1 & 26.3 & 24.7 \\
\hline
\end{tabular}

instead of LEB is again verified; about $25 \%$ of the overall input energy is dissipated by means of plasticity and damage of the elastic stiffness in bridges with POT bearings. The independence of this structural dissipation on the transverse cable arrangement may be also appreciated. Bridges with multiple struts also display significant dissipation, but this is slightly lower than the amount observed in the otherwise equivalent two-strut models. However, this damage is more distributed along the deck for the multiple-strut model, as will be demonstrated in Section 7.4. It has been verified that the energy dissipated through the cyclic damage of the elastic properties $\left(E_{\mathrm{Sd}}\right)$ is much lower than the amount dissipated by the plastic strain $\left(E_{\mathrm{Sp}}\right)$ and the work introduced by the external forces $\left(E_{\mathrm{W}}\right)$.

\subsection{Incremental dynamic analysis}

The results of IDA for models with multiple struts are presented in Figure 11 through the use of the SPI introduced previously in Section 5, again employing the set of six benchmark records. Similar results have been observed for the other configurations of UD-CSB considered in this study. The direction of $\operatorname{SPI}^{j}(j=X, Y, Z)$ depends on the considered force. However, it has been observed that results in terms of vertical bending moments are almost the same if one considers the vertical, horizontal or an average of both directions when the SPI is calculated with expression (2). For that reason, the first option has been selected $(j=Z)$ for the purposes of presenting these results. The improved efficiency (reduced dispersion) in the elastic range using the proposed SPI factor, over using the spectral acceleration for the fundamental mode $\left(S_{\mathrm{a}}\left(T_{1}\right)\right)$, has been verified. For $S_{\mathrm{a}}\left(T_{1}\right)$, significantly different results were obtained considering similar levels of the IM in the linear range, which is due to modal couplings in the vertical plane and the triaxial excitation that $S_{\mathrm{a}}\left(T_{1}\right)$ cannot hope to reflect.

The strong nonlinear response in terms of horizontal bending moments $\left(M_{z z}\right)$ has been observed (especially in models with two struts), and this can be contrasted with the behaviour in terms of axial loads and vertical bending moments, which is closer to a linear response. Beyond the linear response, the same increments of the SPI factor typically lead to successively smaller increments in the structural response measured, because of greater amounts of the seismic energy being dissipated by hysteresis. Nonetheless, one interesting exception arises from Figure 11(a); the first significant cracking of the deck (point A in Figure 11(a)) causes the loss of linearity in the evolution of vertical bending moments with SPI; however, because of the contribution of the cable-system under the deck, the response is again closer to the elastic response immediately beyond this seismic intensity (point B in Figure 11(a)), finally, for very large ground shaking, the hysteretic dissipation is again increased.

Inspection of Figure 11 reveals that the results under near-field records (depicted with dashed lines) are not clearly more demanding than those obtained under far-field records (solid lines) once the same level of the IM is considered. The velocity pulse in near-field records, as has previously been mentioned, is more evident in the horizontal components, whereas the most critical component for the response of these bridges is the vertical. Therefore, although, on the basis of these results alone, it cannot be categorically stated that UD-CSB are not sensitive to near-field effects; the fact that velocity pulses are more apparent in horizontal components may suggest that these bridges are less sensitive than other types of structures. However, although velocity pulses may not play a major role in governing the performance of these bridges, near-field records often tend to have relatively strong vertical components and this generally large demand will clearly be important. 


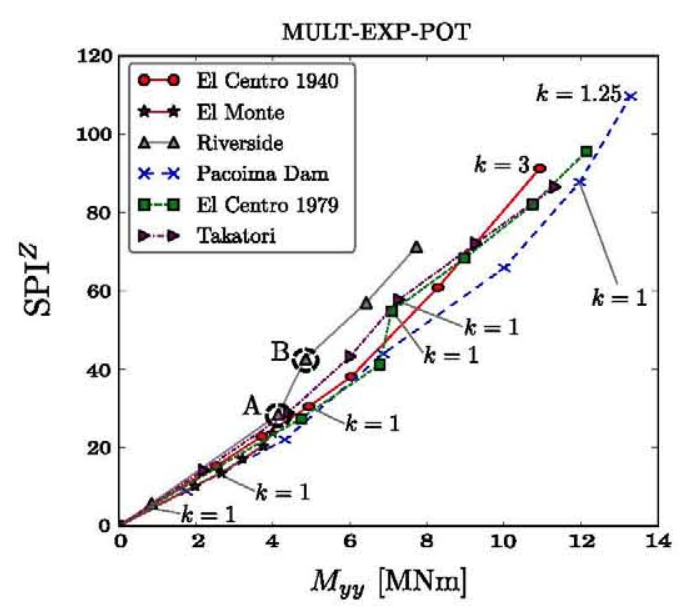

(a)

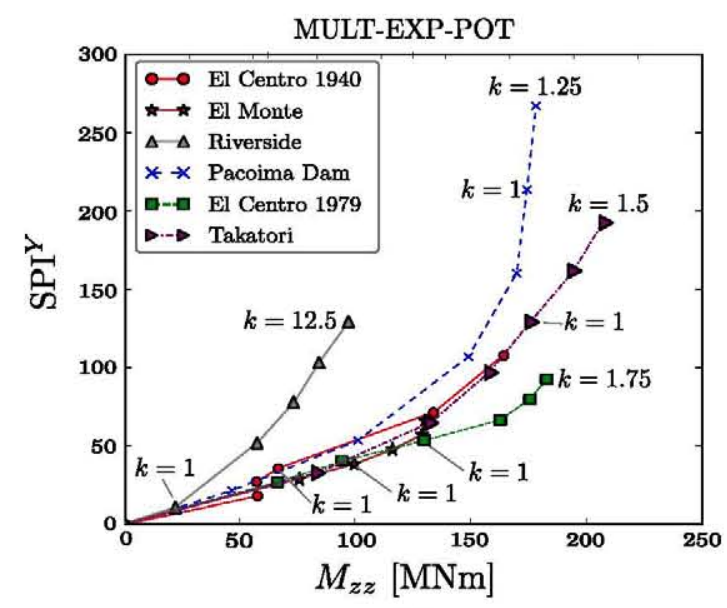

(b)

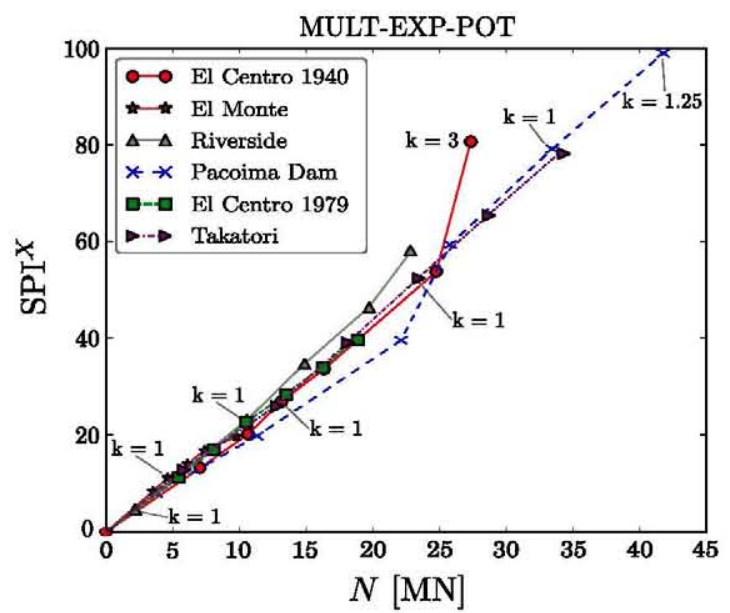

(c)

Figure 11. Several extreme seismic responses due exclusively to the seismic induced loading in terms of the proposed SPI factor considering the set of benchmark records. (a) Extreme absolute vertical bending moment $M_{y y}$; (b) extreme absolute transverse bending moment $M_{z z}$; and (c) extreme absolute axial load $N$. The record scale factor $(k)$ employed in representative cases has been included.

\section{DESIGN VERIFICATION WITH RELEVANT EUROCODES}

The response of the proposed UD-CSB is assessed for the loading scheme defined in Section 3 (nonlinear dynamic analysis), imposing suites of accelerograms that are compliant with Eurocode 8 [20] and that have been presented in Section 4.2. The assessment is made by comparing the horizontal displacements of LEB, the horizontal forces in POT bearings, and the demand in the critical sections along the deck with the respective capacities.

\subsection{Orbit of displacements in laminated elastomeric bearings}

Eurocode 8 states that the average seismic response of the structure may be employed in the design if seven or more records are considered when conducting time-history analysis, which is the case in this work. However, when considering multi-axial response it is not always clear how the averaged response should be evaluated [30]. In this study we consider the orbit of horizontal relative support displacements for each accelerogram within the set and define a rectangle that contains this orbit with sides parallel to the longitudinal and transverse axes of the structure. The average demand is 
then determined as the mean of the half-widths of the rectangle for the seven accelerograms. This average demand is represented by the dashed black rectangle in Figure 12.

Figure 12 illustrates the orbit of horizontal relative displacements in the middle support over the right abutment because of the seven natural records. The average extreme displacements because of the earthquake actions are shown using a dashed black rectangle. The total demand, accounting for the initial elastic deformation and long-term effects $(33 \mathrm{~mm})$ plus the earthquake actions is shown using a black rectangle with a solid line. The maximum allowable displacement, based upon a unit distortion of the bearing [31], is shown by the green shaded area.

This figure demonstrates that the accidental situations including the earthquake actions are critical for the design of the laminated elastomeric bearings, that is, for the scenario considered in this paper, a $700 \times 700 \times 160 \mathrm{~mm}$ bearing would be required (see Figure 12(b)).

\subsection{Horizontal reactions in pot bearings}

The maximum vertical reactions in both Schemes a and $b$ are almost identical $(6 \mathrm{MN})$, and are significantly smaller than the design reaction under persistent situations $(8.5 \mathrm{MN})$. The maximum longitudinal reactions in Schemes a and b are again almost identical (18.6 MN). The current technology for POT bearings allows horizontal reactions that are a relatively low fraction of the vertical load carrying capacity. Therefore, in Scheme a, these horizontal reactions should be accommodated with one of the two following solutions: (1) placing a bearing in a vertical plane and prestressing the deck against the abutment and (2) creating a male-female connection between the deck and the abutment. Both of these solutions are significantly more complicated than Scheme b, which we recommend.

\subsection{Comparison of section capacity and demand using interaction diagrams}

The design verification in the critical sections of the deck has been carried out in all studied models by comparing their capacity and average demand, with the demand being assessed for the load combination defined in Section 4.2. A conservative approximation has been made to simplify the complex comparison between the 3D surface of the interaction diagram and the $3 \mathrm{D}$ curve representing the demand. That being, the extreme value of transverse bending moment is assumed to be experienced at the same time as the worst combination of vertical bending moment and axial load (this is not strictly realistic because the vibration mode governing the transverse response has smaller period than the first vertical mode, see Table II). Hence, a two-dimensional plot of the interaction diagram may be studied. Two values of the extreme transverse bending moment have

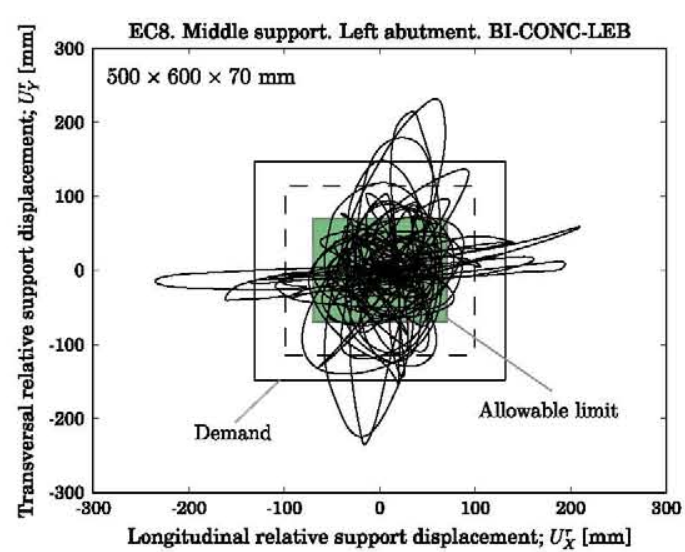

(a)

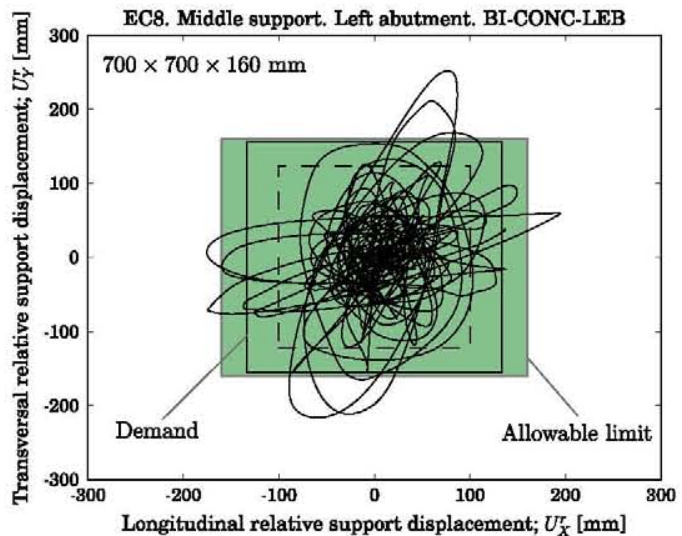

(b)

Figure 12. Orbits of relative horizontal displacements at the supports for: (a) $500 \times 600 \times 70 \mathrm{~mm}$ and

(b) $700 \times 700 \times 160 \mathrm{~mm}$. Results are shown for the BI-CONC-LEB model. Seismic and total demand are represented by dashed and solid lines, respectively, while the shaded area shows the allowable area. 
been used to obtain the interaction diagram: (i) the value produced for the most demanding accelerogram of the set, $M_{z z, \max }^{*}$; and (ii) the average value for the set of seven accelerograms, $\bar{M}_{z z, \max }$ (the latter being more reasonable from a reliability perspective).

The results obtained at the connection of the right strut with the deck, and those at the centre of the central span (which is the location closest to reaching the limit-state), are presented in Figure 13 for the model with two struts and POT bearings arranged in accordance with Scheme b (Figure 3(b)). All UD-CSB models, regardless of the support configuration, satisfy the design check for the considered seismic action everywhere in the deck. This statement is made in the context of Figure 13(b) in which a small part of the envelope orbit slightly exceeds the capacity when the worst transverse moment $M_{z z, \max }^{*}$ is considered. However, the use of this maximum moment is mostlikely overly conservative.

Comparing the results obtained with the records included in Table III, the coefficient of variation for the extreme axial load, transverse and vertical bending moments is found to be approximately $20 \%$, $40 \%$ and $6 \%$, respectively. The large dispersion in the transverse response is due to the significant difference between horizontal spectra (see Figure 7), which is reduced in the vertical direction.

\subsection{Extreme strain along the deck}

Figure 14 presents the extreme tensile and compressive strain recorded along the deck (regardless of the fiber of the section where they are recorded) in different models for each accelerogram of the set, and the average value and the strain limits of elasticity presented in Section 2. Cracking is deemed admissible in this Ultimate Limit State represented by the earthquake combination, because the yield strain of the reinforcement is not exceeded in any proposed bridge, whereas concrete softening slightly appears in the longitudinally constrained side span if the supports are changed from LEB to POT bearings. In the model with LEB, cracking is concentrated in the lateral subspans (between the struts and the abutments) and the area close to the connection of the diverting struts and the deck. On the other hand, in models with POT bearings, the right-half of the deck, next to the abutment with longitudinally fixed supports, shows enlarged levels of cracking because of higher values of seismic-induced axial load. Finally, comparing Figures 14(b) and (14), the decrease of cracking along the deck when multiple struts are considered can be observed, and this is due to the reduction in the vertical bending moment along the deck (see Figure 9(a)).

Tensile strains are larger than their compressive counterparts because of fragile cracking propagation; once the cracking strain limit is exceeded in one integration point, tensile strain is

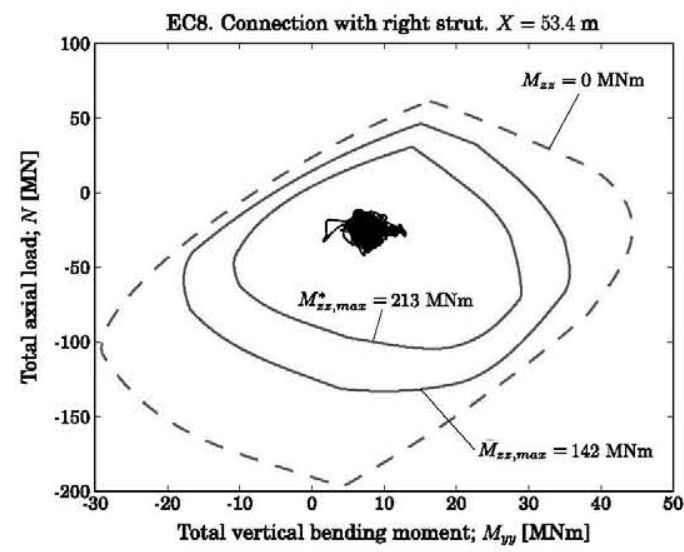

(a)

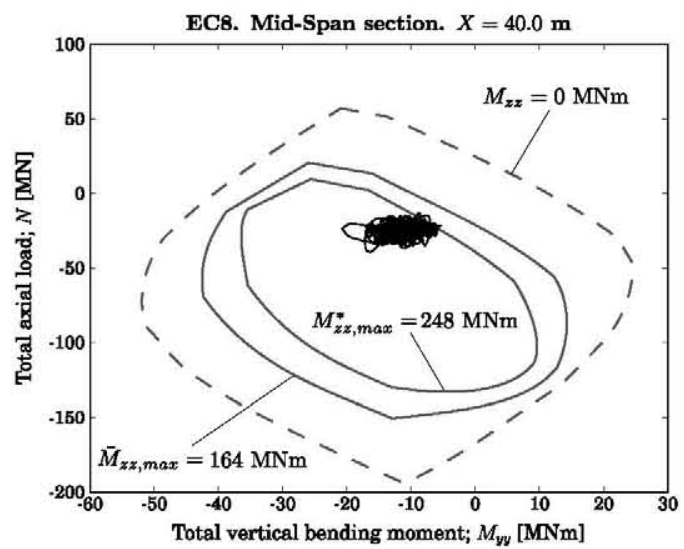

(b)

Figure 13. Design check: comparison between the envelope orbit demand (total $M_{y y}$ and total $N$ ) and the interaction diagram for two significant values of transverse bending moment. The dashed line corresponds to $M_{z z}=0 \mathrm{MNm}$. EC8 seismic action. BI-CONC-POT model with Scheme b in POT support configuration. (a) Section of the deck in contact with the right inclined strut $(X=53.4 \mathrm{~m})$; (b) Section of the deck in the midspan $(X=40 \mathrm{~m})$ 


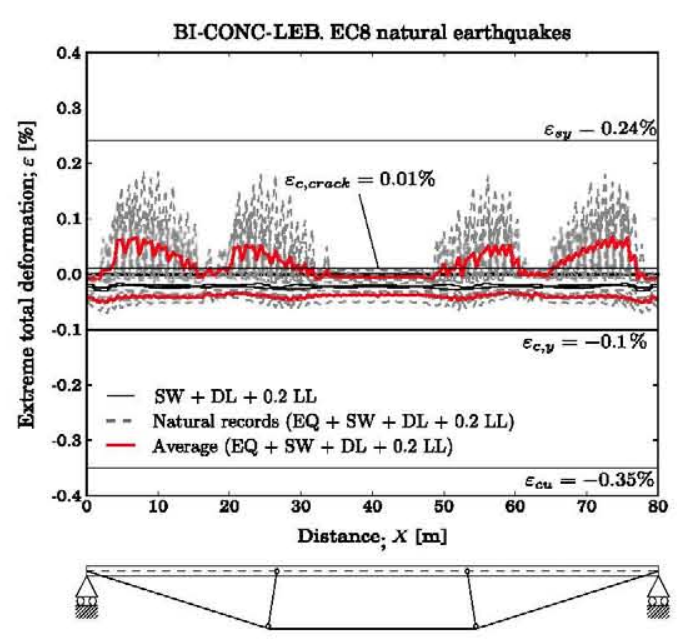

(a)

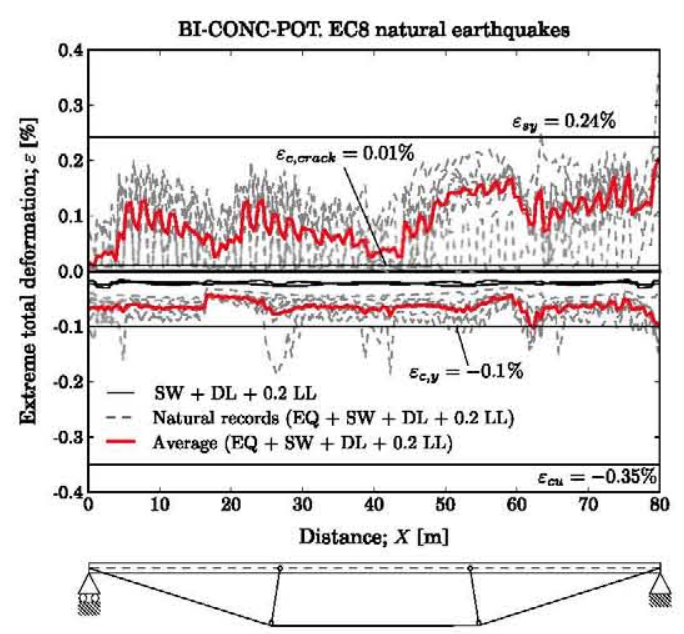

(b)

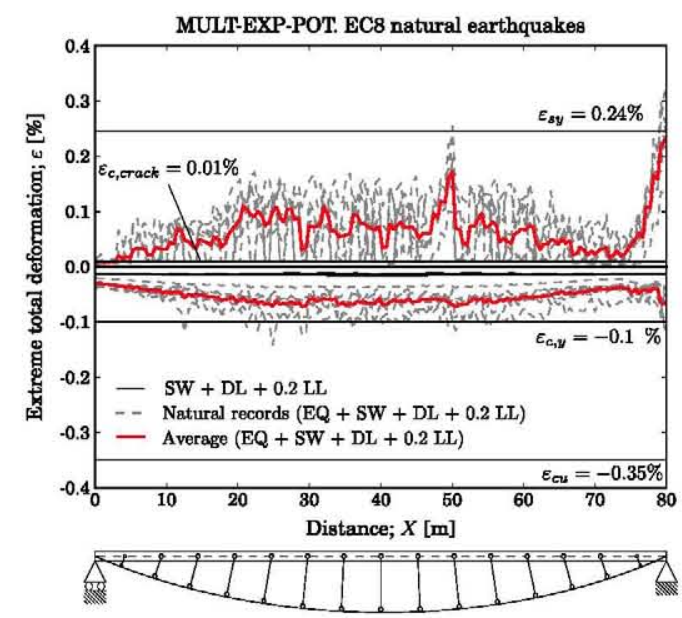

(c)

Figure 14. Distribution of the extreme total strain [\%] of the deck along its length (Earthquake (EQ)+ SelfWeight (SW) + superimposed Dead-Load (DL) $+20 \%$ Live-Load (LL)) with each natural record included in the set of Eurocode 8 seismic action. Concrete cracking, elastic and ultimate limits strains are included. (a) Two struts and LEB supports; (b) two struts and POT bearings (scheme a); and (c) multiple struts and POT bearings.

rapidly concentrated in this area, which explains the sawtooth distribution of the extreme tensile strain along the deck.

\section{CONCLUSIONS}

The seismic behaviour of single-span under-deck cable-stayed bridges has been studied by means of detailed finite element models, considering several design possibilities to address their influence in the response. First, benchmark records with and without near-fault effects have been studied, applying different scale factors to explore the nonlinear seismic behaviour of these structures. The work finished with the study of the response under the seismic excitation described by a set of seven natural records matching the Type 1 Eurocode 8 spectra. The following conclusions about the seismic response of this promising typology can now be made: 
1. The seismic response of UD-CSB is more robust than that obtained in conventional bridges with intermediate piers. If the seismic excitation exceeds the anticipated demand, and extensive cracking arises along the deck, its vertical stiffness decreases and the cable-system, which remains elastic, assumes more participation in the overall resistance. This enhances the effectiveness of the cable-stays and provides an excellent way for the structure to survive the earthquake. Moreover, the removal of the intermediate piers is advantageous given that they are among the most sensitive components in classical bridges under seismic excitation. Previous research $[6,8]$ has proved that single-span UD-CSB represent an economic and efficient solution for medium spans $(\approx 80 \mathrm{~m})$ in aseismic conditions. Their robust seismic performance has now also been verified.

2. For UD-CSB bridges, the deck, struts and cables designed for persistent situations without consideration of imposed ground accelerations, resist Eurocode 8 compliant seismic actions appropriate for high-seismic areas (employing $a_{\mathrm{g}}=0.4 \mathrm{~g}$ ). Only the bearings require larger capacity under these conditions.

3. The use of LEB significantly reduces the seismic demand in the superstructure, but relatively large bearings are required to accommodate the relative displacements at the supports. For bridges located in seismic areas, we recommend the use of laminated elastomeric bearings over POT bearings because of their ability to isolate the superstructure. POT bearings constrain the deformation of the bridge, resulting in a loss of symmetry of the response and notably increasing the seismic demand along the whole structure. If POT devices need to be included because of excessive support displacements, the statically determinate layout (Scheme b in Figure 3) is recommended.

4. Under-deck cable-stayed bridges with multiple (15) diverting struts improve the seismic response compared with solutions employing two struts. The typology with multiple struts spreads the damage along the deck.

5. The influence of the transverse cable arrangement, concentrated or expanded, is not of great importance for the seismic behaviour of UD-CSB.

6. A new intensity measure referred to as SPI has been proposed. This intensity measure accounts for multiple attributes of both the structure and the ground-motion and is far more efficient than traditional IMs such as the spectral acceleration in the fundamental period $\left(S_{\mathrm{a}}\left(T_{1}\right)\right)$. SPI is based on the summation of the product of the participation factor and the spectral acceleration over the whole range of vibration modes, which contribute significantly to the overall dynamic response. SPI gives an idea about the seismic energy affecting any structure (not only bridges with nonconventional cable-systems) in each direction prior to the seismic analysis. Only modal analysis and the acceleration spectrum are required, which makes its calculation relatively straightforward.

\section{REFERENCES}

1. Walther R, Houriet B, Isler W, Moïa P, Klein JF. Cable-stayed bridges. Thomas Telford, 1988.

2. Gimsing N. Cable supported bridges: Concept and design (2nd edn). John Wiley and Sons: New York, 1997.

3. Chio G. Structural behaviour and design criteria of extradosed bridges. PhD Thesis, Technical University of Catalonia, Spain, 2000.

4. Abdel-Ghaffar A. Cable-stayed bridges under seismic action. Cable-stayed bridges; recent developments and their future. Elsevier Science Ltd.: Yokohama, 1991; 171-192.

5. Walker C, Stafford PJ. The use of modal-combination rules with cable-stayed bridges. Proceedings of the Institution of Civil Engineers: Bridge Engineering 2010; 163:225-240.

6. Ruiz-Teran AM, Aparicio AC. Two new types of bridges: under-deck cable-stayed bridges and combined cablestayed bridges - the state of the art. Canadian Joumal of Civil Engineering 2007; 34(8):1003-1015.

7. Ruiz-Teran AM, Aparicio AC. Parameters governing the response of under-deck cable-stayed bridges. Canadian Journal of Civil Engineering 2007; 34(8):1016-1024.

8. Ruiz-Teran AM, Aparicio AC. Structural behaviour and design criteria of under-deck cable-stayed bridges and combined cable-stayed bridges. Part I: single-span bridges. Canadian Journal of Civil Engineering 2008; 35:938-950.

9. Ruiz-Teran AM, Aparicio AC. Structural behaviour and design criteria of under-deck cable-stayed bridges and combined cable-stayed bridges. Part II: multispan bridges. Canadian Journal of Civil Engineering 2008; 35:951-962.

10. Ruiz-Teran AM, Aparicio AC. Eliminating bridge piers using stay cables with unconventional layouts. Proceedings of the International FIB Symposium 2008, 'Tailor made concrete structures: new solutions for our society', Amsterdam, 2008. 
11. Ruiz-Teran AM, Aparicio AC. Response of under-deck cable-stayed bridges to the accidental breakage of stay cables. Engineering Structures 2009; 26:1425-1434.

12. Ruiz-Teran AM, Aparicio AC. Developments in under-deck and combined cable-stayed bridges. Proceedings of ICE Bridge Engineering 2010; 163(2):67-78.

13. Ruiz-Teran AM. Unconventional cable-stayed bridges. Structural behaviour and design criteria. Structural Concrete 2010; 11(1):25-34.

14. Ruiz-Teran AM, Aparicio AC. Nonlinear behaviour of under-deck cable-stayed bridges. Proceedings of the $5^{\text {th }}$ International ACHE Conference on Structures, Barcelona, 2011.

15. Vamvatsikos D, Cornell CA. Incremental Dynamic Analysis. Earthquake Engineering and Structural Dynamics 2002; 31(3):491-514.

16. Shome N, Cornell CA, Bazzurro P, Carballo E. Earthquakes, records, and nonlinear response. Earthquake Spectra 1998; 14(3):469-500.

17. Luco N, Cornell CA. Structure-specific scalar intensity measures for near-source and ordinary earthquake ground motions. Earthquake Spectra 2007; 23(2):357-392.

18. Baker JW, Cornell CA. Ground motion scaling methods for different site conditions and structural characteristics. Earthquake Engineering and Structural Dynamics 2003; 32(15):2425-2450.

19. Baker JW, Cornell CA. Spectral shape, epsilon and record selection. Earthquake Engineering and Structural Dynamics 2006; 35(9):1077-1095.

20. Comité Européen de Normalisation. Eurocode 8, Design of structures for earthquake resistance - Part 1: general rules, seismic actions, and rules for buildings. EN 1998-1:2004, 2004.

21. Ramberger G. Structural Bearings and Expansion Joints for Bridges. IABSE, Structural Engineering Documents 6 , Switzerland, 2002; ISBN 3-85748-105-6.

22. ABAQUS. Finite element analysis program, version 6.10, Providence, USA, 2010.

23. Chopra AK. Dynamics of Structures: theory and application to earthquake engineering (3rd edn). Prentice Hall: New Jersey, 2007.

24. Mazars J, Pijaudier-Cabot G. Continuum damage theory - application to concrete. Journal of Engineering Mechanics 1989; 115(2):345-365

25. Comité Européen de Normalisation. Eurocode 2, Design of concrete structures - Part 1-1: General - common rules for buildings and civil engineering structures. EN 1992-1-1:2004, 2004.

26. Fleming J, Egeseli E. Dynamic behaviour of a cable-stayed bridge. Earthquake Engineering and Structural Dynamics $1980 ; \mathbf{8}: 1-16$.

27. Hilber H, Hughes $\mathrm{T}$, Taylor R. Improved numerical dissipation for time integration algorithms in structural dynamics. Earthquake Engineering and Structural Dynamics 1977; 5:283-292.

28. Bommer JJ, Stafford PJ, Alarcón JE. Empirical equations for the prediction of the significant, bracketed and uniform duration of earthquake ground motion. Bulletin of the Seismological Society of America 2009; 99(6):3217-3233.

29. Bommer JJ, Acevedo A. The use of real accelerograms as input to dynamic analysis. Journal of Earthquake Engineering 2004; 8(special issue 1):43-91.

30. Priestley MJN. Seismological Information for displacement-based design - a structural engineer's wish list. Proceedings of the First European Conference on Earthquake Engineering and Seismology, Geneva, Switzerland, Paper K1-A, 2006.

31. Comité Européen de Normalisation. EN 1337-3:2005 Structural bearings. Part 3: Elastomeric bearings, 2005. 